\title{
Article \\ Supramolecular Self-Assembly of Atomically Precise Silver Nanoclusters with Chiral Peptide for Temperature Sensing and Detection of Arginine
}

\author{
Wenjuan Wang, Zhi Wang, Di Sun (D), Shulin Li, Quanhua Deng and Xia Xin *D
}

check for updates

Citation: Wang, W.; Wang, Z.; Sun,

D.; Li, S.; Deng, Q.; Xin, X.

Supramolecular Self-Assembly of Atomically Precise Silver

Nanoclusters with Chiral Peptide for Temperature Sensing and Detection of Arginine. Nanomaterials 2022, 12, 424. https://doi.org/10.3390/ nano12030424

Academic Editor: Rodolphe Antoine

Received: 23 December 2021

Accepted: 24 January 2022

Published: 27 January 2022

Publisher's Note: MDPI stays neutral with regard to jurisdictional claims in published maps and institutional affiliations.

Copyright: (C) 2022 by the authors. Licensee MDPI, Basel, Switzerland. This article is an open access article distributed under the terms and conditions of the Creative Commons Attribution (CC BY) license (https:// creativecommons.org/licenses/by/ $4.0 /)$.

\author{
National Engineering Research Center for Colloidal Materials, Key Laboratory of Colloid and Interface \\ Chemistry (Ministry of Education), School of Chemistry and Chemical Engineering, Shandong University, \\ Jinan 250100, China; wenjuanwang@mail.sdu.edu.cn (W.W.); zwang@mail.sdu.edu.cn (Z.W.); \\ dsun@sdu.edu.cn (D.S.); 202032370@mail.sdu.edu.cn (S.L.); qhdeng@sdu.edu.cn (Q.D.) \\ * Correspondence: xinx@sdu.edu.cn; Tel.: +86-531-8836-3597
}

\begin{abstract}
Metal nanoclusters (NCs) as a new type of fluorescent material have attracted great interest due to their good biocompatibilities and outstanding optical properties. However, most of the studies on metal NCs focus on the synthesis, atomic or molecular assembly, whereas metal NCs ability to self-assemble to higher-level hierarchical nanomaterials through supramolecular interactions has rarely been reported. Herein, we investigate atomic precise silver NCs $\left(\mathrm{Ag}_{9}-\mathrm{NCs},\left[\mathrm{Ag}_{9}(\mathrm{mba})_{9}\right]\right.$, where $\mathrm{H}_{2} \mathrm{mba}=$ 2-mercaptobenzoic acid) and peptide DD-5 were used to induce self-assembly, which can trigger an aggregation-induced luminescence (AIE) effect of $\mathrm{Ag}_{9}-\mathrm{NCs}$ through non-covalent forces (H-bond, $\pi-\pi$ stacking) and argentophilic interactions [ $\mathrm{Ag}(\mathrm{I})-\mathrm{Ag}(\mathrm{I})]$. The large Stokes shift $(\sim 140 \mathrm{~nm})$ and the microsecond fluorescence lifetime $(6.1 \mu \mathrm{s})$ indicate that $\mathrm{Ag}_{9}-\mathrm{NCs} / \mathrm{DD}-5$ hydrogel is phosphor. At the same time, the chirality of the peptide was successfully transferred to the achiral $\mathrm{Ag}_{9}$-NCs because of the supramolecular self-assembly, and the Ag-NCs/DD-5 hydrogel also has good circularly polarized luminescence (CPL) properties. In addition, $\mathrm{Ag}_{9}$-NCs/DD-5 luminescent hydrogel is selective and sensitive to the detection of small biological molecule arginine. This work shows that DD-5 successfully induces the self-assembly of $\mathrm{Ag}_{9}$-NCs to obtain high luminescent gel, which maybe become a candidate material in the fields of sensors and biological sciences.
\end{abstract}

Keywords: supramolecular self-assembly; metal nanoclusters; peptide; aggregation-induced emission; chirality

\section{Introduction}

As a bridge between atom and nanoparticle, metal nanoclusters (metal NCs, mainly $\mathrm{Au}, \mathrm{Ag}$ and $\mathrm{Cu}$ ) which are composed of a few to hundreds of mental atoms and covered with organic ligands on the surface of the metal core, have been receiving extensive attention due to their important roles in the fields of catalysis, sensing, electrochemistry, energy transfer and biomedicine [1-5]. Among various applications, metal nanoclusters are widely used as sensors because of their sensitive responses to temperature, $\mathrm{pH}$ value, metal ions and small biological molecules [6-10]. For example, Hu et al. utilized $\mathrm{Cu}-\mathrm{MOF}$ as a precursor to prepare highly stable $\mathrm{Cu}$ NCs, which can be used to construct a $\mathrm{pH}$ ratiometric fluorescence sensor to monitor $\mathrm{pH}$ of microorganism [8]. Kailasa et al. found that the addition of $\mathrm{La}^{3+}$ can significantly enhance the fluorescence emission of BSA-AuNCs, and constructed an $\mathrm{La}^{3+}$ ion-BSA-AuNCs fluorescence sensor, thus realizing the detection of four divalent metal ions $\left(\mathrm{Hg}^{2+}, \mathrm{Cy}^{2+}, \mathrm{Pb}^{2+}\right.$ and $\left.\mathrm{Cd}^{2+}\right)$ [9].

In particular, the biocompatibility and fluorescent properties are potentially useful in biological systems of Ag NCs, making them a research hotspot [11]. However, the current research on Ag NCs is mainly focused on the synthesis and atomic or molecular assembly, while the nanostructures obtained by the means of supramolecular self-assembly are rarely 
reported [12,13]. This may be due to the small size of the Ag NCs, and to the higher surface energy inducing further growth of Ag NCs into larger Ag nanoparticles, which is not conducive to the progress of self-assembly. Therefore, in order to solve this problem, the subtle non-covalent interactions (H-bond, $\pi-\pi$ stacking, van der Waals forces, electrostatic interactions and hydrophobic interaction) should be controlled between Ag NCs by adding small molecules through supramolecular self-assembly to obtain ordered aggregates.

As a natural biomolecule, peptides are usually composed of less than 50 amino acids, are easy to manipulate and synthesize, and can self-assemble into various ordered aggregates, such as nanotubes, nanofibers, nanovesicles, nanobelts and hydrogel [14-18]. However, in order to overcome the inherent limitations of single-component materials and make multi-component materials more widely used, peptides can be co-assembled with a variety of functional molecules to obtain supramolecular materials [19-21]. For example, Gazit et al., through the co-assembly between Fmoc-RGD and chitosan, obtained a hydrogel with stronger mechanical properties and stronger durability than Fmoc-RGD self-assembled hydrogel, which has a wide range of applications in the field of cell culture scaffolds [22]. Xu et al. obtained the hydrogel of nanofibers through coordination, $\mathrm{H}$-bond and hydrophobic interaction between hairpin peptides and copper ions, and the nanofibers can be utilized as templates for the synthesis of long, ultrathin CuS nanowires which have near-infrared (NIR) laser-induced thermal effect [23]. Therefore, using peptides to induce the self-assembly of Ag NCs can not only improve the biocompatibility of multi-component materials, but also expand the range of application for metal NCs-based materials [6,7,24].

In this work, we used water-soluble, atomically precise $\mathrm{Ag} \mathrm{NCs}\left(\mathrm{Ag}_{9}-\mathrm{NCs},\left[\mathrm{Ag}_{9}(\mathrm{mba})_{9}\right]\right.$, where $\mathrm{H}_{2} \mathrm{mba}=2$-mercaptobenzoic acid) to interact with the peptide DD-5 to construct luminescent hydrogel. The Ag-NCs/DD-5 hydrogel was realized through non-covalent forces (H-bond, $\pi-\pi$ stacking) and argentophilic interactions $[\mathrm{Ag}(\mathrm{I})-\mathrm{Ag}(\mathrm{I})]$, and phosphorescent emission was obtained through aggregation-induced luminescence (AIE). The $\mathrm{Ag}_{9}-\mathrm{NCs} / \mathrm{DD}-5$ xerogel has good application in temperature sensing and the orange-red emission of the hydrogel can be used to detect arginine (Scheme 1). This work provides a new example for the construction of metal NC-peptide complexes through non-covalent bonds used in the fields of temperature fluorescence sensing and biological detection.

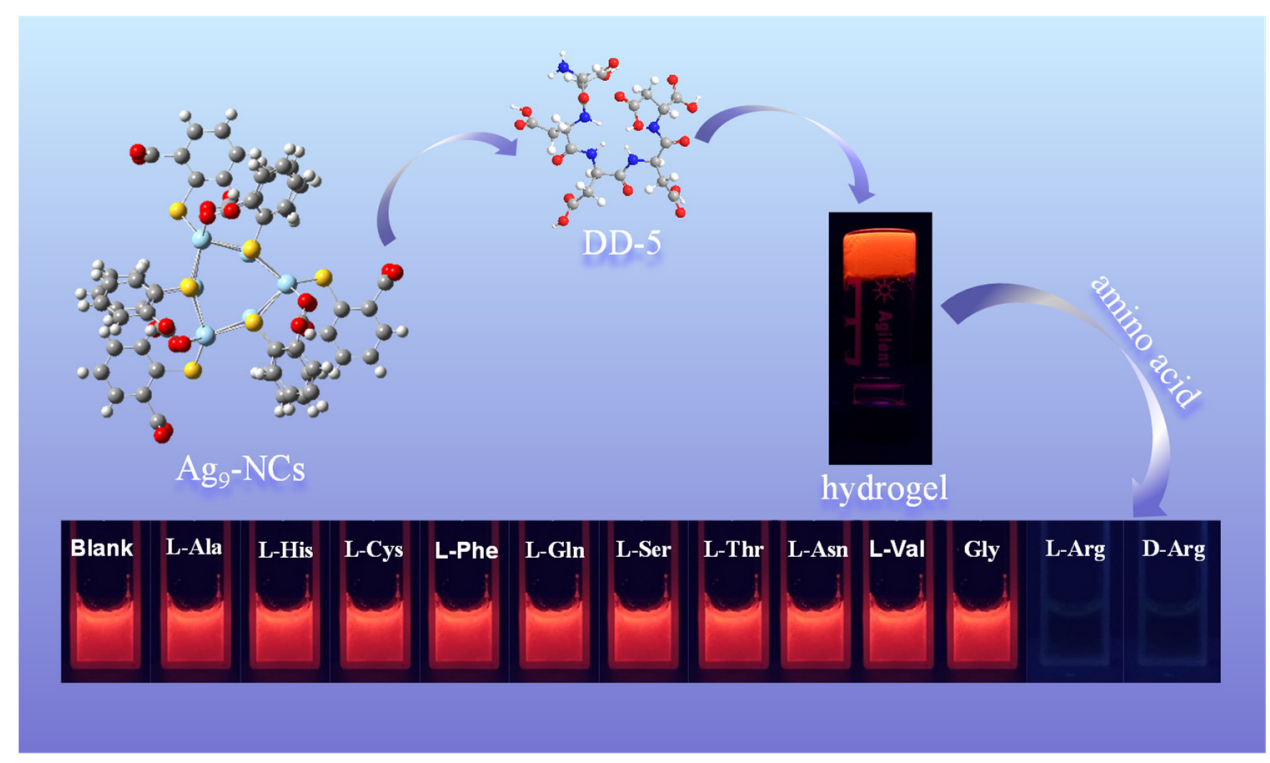

Scheme 1. Schematic illustration of the self-assembly of the $\mathrm{Ag}_{9}-\mathrm{NCs}$ driven by DD-5 and their application in the detect of Arginine. 


\section{Materials and Methods}

\subsection{Materials}

The synthesis, purification and detailed characterization of $\mathrm{Ag}_{9}-\mathrm{NC}$ s can be found in literature [6,25]. DD-5 was purchased from GL Biochem Ltd. (Shanghai, China) and used without further purification. It was polymerized by five aspartic acids and its relative molecular mass was $593.46 \mathrm{~g} \mathrm{~mol}^{-1}$. The molecular structure of DD-5 is shown in Figure 1a. L-Arginine (L-Arg), D-Arginine (D-Arg), L-alanine (L-Ala), L-histidine (L-His), L-cysteine (L-Cys), L-phenylalanine (L-Phe), L-tyrosine (L-Tyr), L-asparagine (L-Asn), L-valine (L-Val) and glycine (Gly) were purchased from Sinopharm Chemical Reagent Co., Ltd, (Shanghai, China). L-Glutamine (L-Glu) and L-serine (L-Ser) were purchased from Sigma-Aldrich (St. Louis, MO, USA). Ultrapure water used in the experiments with a resistivity of $18.25 \mathrm{M} \Omega \mathrm{cm}^{-1}$ was obtained using a UPH-IV ultrapure water purifier (Shanghai Youpu Industry Company Ltd., Shanghai, China).
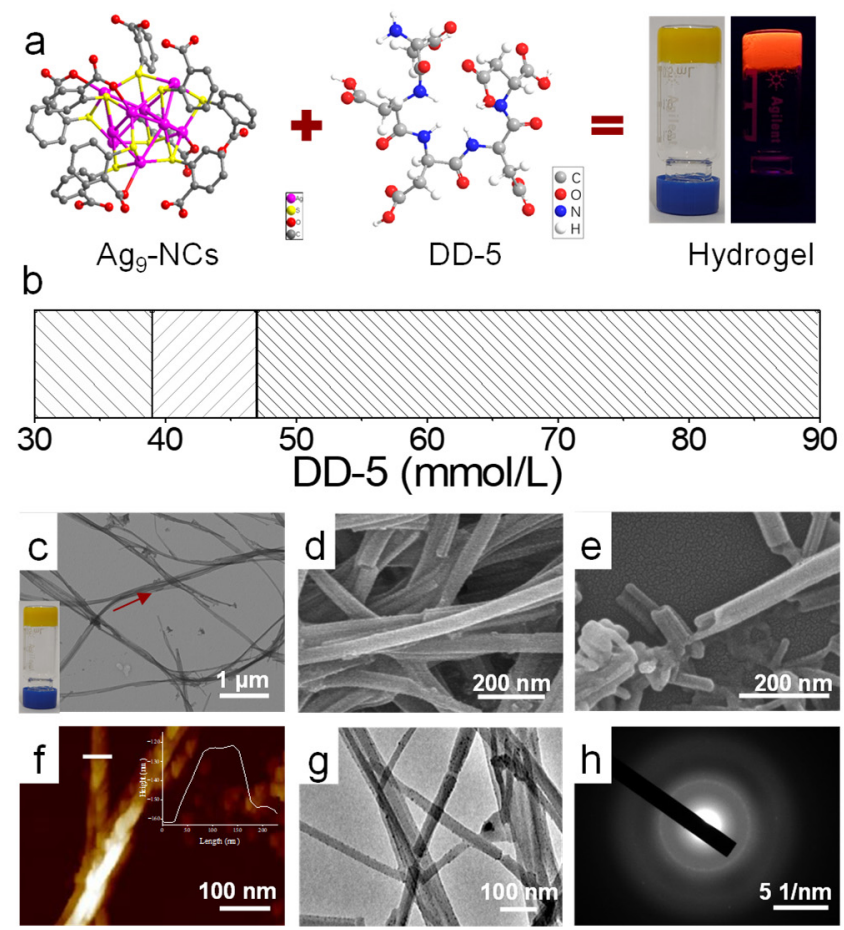

Figure 1. Self-assembly phase behavior and detailed characterization of $5 \mathrm{mM} \mathrm{Ag} 9-\mathrm{NCs} / 70 \mathrm{mM}$ DD-5 hydrogel. (a) The structure of $\mathrm{Ag}_{9}-\mathrm{NCs}$ and DD-5, the schematic diagram of the formation of the core sample hydrogel; (b) the concentration of $\mathrm{Ag}_{9}-\mathrm{NCs}$ was fixed at $5 \mathrm{mM}$, and the concentration of DD-5 was changed to obtain a phase diagram; (c) TEM, the inset is a visual diagram of the sample; (d,e) SEM; (f) AFM, inset: a plan view of the height extending from the indicator line; (g) HR-TEM; (h) SAED pattern of HR-TEM.

\subsection{Self-Assembly of Ag9-NCs/DD-5 Hydrogel}

In this typical experiment, we added $20.0 \mathrm{mg}$ DD-5 to $355 \mu \mathrm{L}$ ultrapure water and stirred, then added $145 \mu \mathrm{L} \mathrm{Ag}_{9}$-NCs solution $(15.87 \mathrm{mM})$ and stirred. The hydrogel was successfully prepared after $8 \mathrm{~h}$ of constant temperature $\left(20^{\circ} \mathrm{C}\right)$ in a thermostat. The hydrogel was lyophilized in a vacuum extractor at $-60^{\circ} \mathrm{C}$ for 5 days to collect the orangeyellow powder.

\subsection{The Detection of L-Arg and D-Arg}

Amino acids were added to the solution of DD-5 and $\mathrm{Ag}_{9}-\mathrm{NC}$ s to ensure that the final concentration of amino acids was $100 \mathrm{mM}$. After incubating in $20{ }^{\circ} \mathrm{C}$ incubator for $8 \mathrm{~h}$, we performed a fluorescence test to study the selectivity of the hydrogel toward L-Arg and D-Arg, because both D-Arg and L-Arg can completely quench the fluorescence of 
nanotubes. We took L-Arg as an example to investigate in detail: we added different concentrations of L-Arg to the formed $100 \mu \mathrm{L}$ of $\mathrm{Ag}_{9}-\mathrm{NCs} / \mathrm{DD}-5$ hydrogel, and placed it in a thermostat at $20^{\circ} \mathrm{C}$ for $8 \mathrm{~h}$. We used a triangular cuvette with a capacity of $2 \mathrm{~mL}$ for fluorescence detection to obtain concentration change spectra.

\subsection{Characterizations}

A copper mesh was inserted into the gel to obtain a sample, and after drying under an IR lamp for $45 \mathrm{~min}$, transmission electron microscopy (TEM) images were observed under a JCR-100CX II (JEOL, Tokyo, Japan) microscope. Field emission scanning electron microscopy (FE-SEM) observations were carried out on a Hitachi SU8010 (Hitachi, Tokyo, Japan) under $10 \mathrm{kV}$. High-resolution TEM (HRTEM) images and selected area electron diffraction (SAED) were recorded by HR-JEOL 2100 (JEOL, Tokyo, Japan) system with an accelerating voltage of $200 \mathrm{kV}$. Atomic force microscope (AFM) tapping mode measurements were performed on Bruke Bioscope Resolve. UV-vis data were recorded on a Shimadzu UV-2600 spectrophotometer (Shimadzu, Kyoto, Japan). Fluorescence data were tested on a LS-55 spectrofluorometer (PerkinElmer, Waltham, MA, USA) and an Edinburgh Instruments FLS920 luminescence spectrometer (xenon lamp, $450 \mathrm{~W}$ ) (Edinburgh Instruments Ltd., Livingston, UK). Fourier transform infrared (FT-IR) spectra in KBr wafer were recorded on a VERTEX-70/70v spectrophotometer (Bruker, Billerica, MA, USA). CD spectra were taken on J-810 Spectra Manager system (ChirascanV 100). Small-angle X-ray spectroscopy (SAXS) measurements were performed using an Anton-Paar SAX Sess mc ${ }^{2}$ system (Anton Paar, Graz, Austria) with nickel-filtered $\mathrm{Cu} \mathrm{K} \alpha$ radiation (1.54 ̊) operating at $50 \mathrm{kV}$ and $40 \mathrm{~mA}$. X-ray diffraction (XRD) patterns were taken on a D8 ADVANCE (Bruker, Germany) diffractometer equipped with $\mathrm{Cu} \mathrm{K} \alpha$ radiation and graphite monochromator. X-ray photoelectron spectroscope (XPS) date were collected by an X-ray photoelectron spectrometer (ESCALAB 250, Thermo Fisher Scientific, Waltham, MA, USA) with a monochromatized AI $\mathrm{K} \alpha \mathrm{X}$-ray source $(1486.71 \mathrm{eV})$. The rheological measurements were carried out on an MARS60 rheometer (Thermo Fisher Scientific, Waltham, MA, USA) with a cone-plate system. Before the frequency sweep, an amplitude sweep at a fixed frequency of $1 \mathrm{~Hz}$ was carried out to ensure that the selected stress was in the linear viscoelastic region. The frequency sweep was carried out from 0.01 to $100 \mathrm{~Hz}$ at a fixed stress of $10 \mathrm{~Pa}$. The variable temperature spectrum is recorded in the UV-Vis-microspectrophotometer $(20 / 30$ $\mathrm{PV}^{\mathrm{TM}}$, Craic Technologies, San Dimas, CA, United States). Thermogravimetric analyses (TGA) were performed under a nitrogen atmosphere at $25-1000{ }^{\circ} \mathrm{C}$ with a heating speed of $10{ }^{\circ} \mathrm{C} \min ^{-1}$ on a TA SDT Q600 thermal analyzer (TA Instruments, New Castle, DE, USA).

\section{Results}

\subsection{Self-Assembly of $A g_{9}-N C s / D D-5$ Hydrogel}

The average diameter of $\mathrm{Ag}_{9}-\mathrm{NC}$ s in the aqueous solution was about $1.4 \pm 0.5 \mathrm{~nm}$, and they were in a non-fluorescent state (Figure S1a). We wonder whether DD-5 peptides, which are non-fluorescent at room temperature, can be used to induce the AIE effect of Ag9-NCs through a self-assembly strategy (Figure S1b). The schematic diagram of the core sample self-assembly is shown in Figure 1a. The concentration of $\mathrm{Ag}_{9}-\mathrm{NC}$ was fixed at $5 \mathrm{mM}$, the concentration of DD-5 was changed, and after incubation for $8 \mathrm{~h}$, the phase diagram was obtained (Figure 1b). Under $365 \mathrm{~nm}$ UV light, the solution state (30 38 mM DD-5) did not emit fluorescence, while the precipitated state (38 47 mM DD-5) and the hydrogel state (47 90 mM DD-5) both emitted orange-red fluorescence (Figure S1c), which implied that as the concentration of DD-5 increases, $\mathrm{Ag}_{9}-\mathrm{NC}$ s gelation restricted the rotation or vibration of the $\mathrm{Ag}_{9}$-NCs ligand on the spatial scale, enhancing AIE and emitted fluorescence.

From the TEM and SEM images, it was found that the precipitate was a solid nanorod structure, and the hydrogel was hollow nanotube with a little spiral (Figure S2). When $c_{\text {DD-5 }}=70 \mathrm{mM}$, it is located in the center of the hydrogel and its morphology is better (Figure S2), so it is defined as the core sample for follow-up research. The microstructures within the hydrogel were characterized in detail by imaging studies. TEM shows that the 
fibers formed in $5 \mathrm{mM} \mathrm{Ag}{ }_{9}-\mathrm{NCs} / 70 \mathrm{mM}$ DD-5 hydrogel were about 30-50 $\mathrm{nm}$ in width and 5-20 $\mu \mathrm{m}$ micrometers in length (Figure 1c,d) and the inside of the fiber had lower contrast than the edge (Figure 1c,g). The fracture surface observed by SEM (Figure 1d,e) indicated that the fibers were hollow nanotube structures. AFM image shows that the thickness of the nanotube was $40 \mathrm{~nm}$, which was basically the same as the width of nanotubes (Figure 1f). In addition, SAED results in Figure $1 \mathrm{~h}$ indicate that the nanotubes were a polycrystalline structure.

\subsection{Fluorescence and Chirality of $A g_{9}-N C s / D D-5$ Hydrogel}

As metal NCs are known as potential AIE molecules, we next explored the fluorescent properties of $\mathrm{Ag}_{9}-\mathrm{NC}$ / DD-5 hydrogel. In the solution state of $\mathrm{Ag}_{9}-\mathrm{NCs}$, due to the free vibration or rotation of the ligand $\mathrm{mba}^{2-}$, the non-radiative inactivation channel is opened and the fluorescence disappears. Therefore, $\mathrm{Ag}_{9}-\mathrm{NC}$ s have a shorter fluorescence lifetime $(\sim 3.277 \mathrm{~ns})$ (Figure S3a, Table S1). However, under the excitation wavelength of $490 \mathrm{~nm}$, the quantum yield of the $\mathrm{Ag}_{9}-\mathrm{NCs} / \mathrm{DD}-5$ hydrogel is $8.11 \%$ with a microsecond fluorescence lifetime $(\sim 6.10 \mu \mathrm{s})$, and the emission wavelength is located at $630 \mathrm{~nm}$ with a large Stokes shift ( 140 nm) (Figures 2a and S3b, Table S2), indicating that it is essentially a phosphor.

a
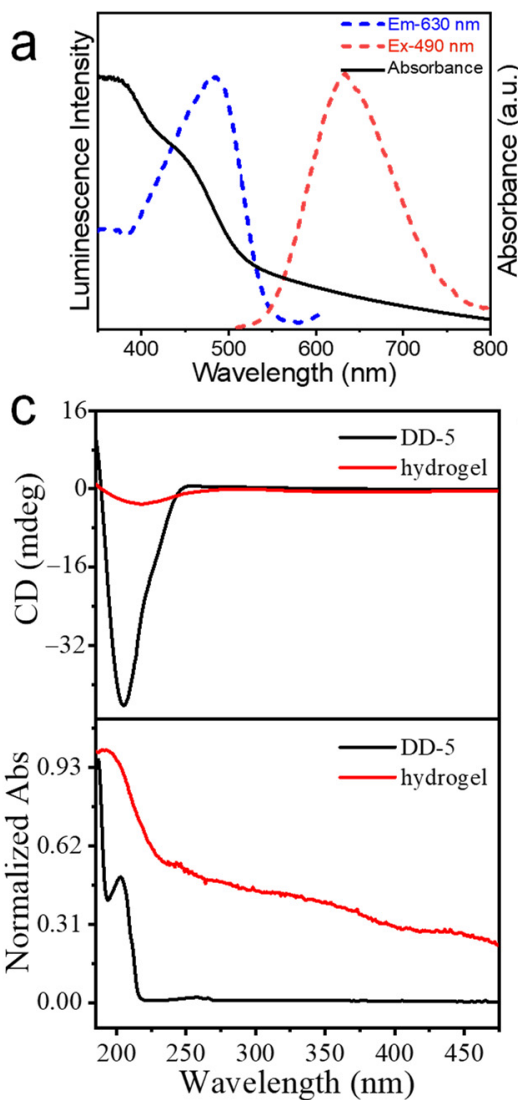
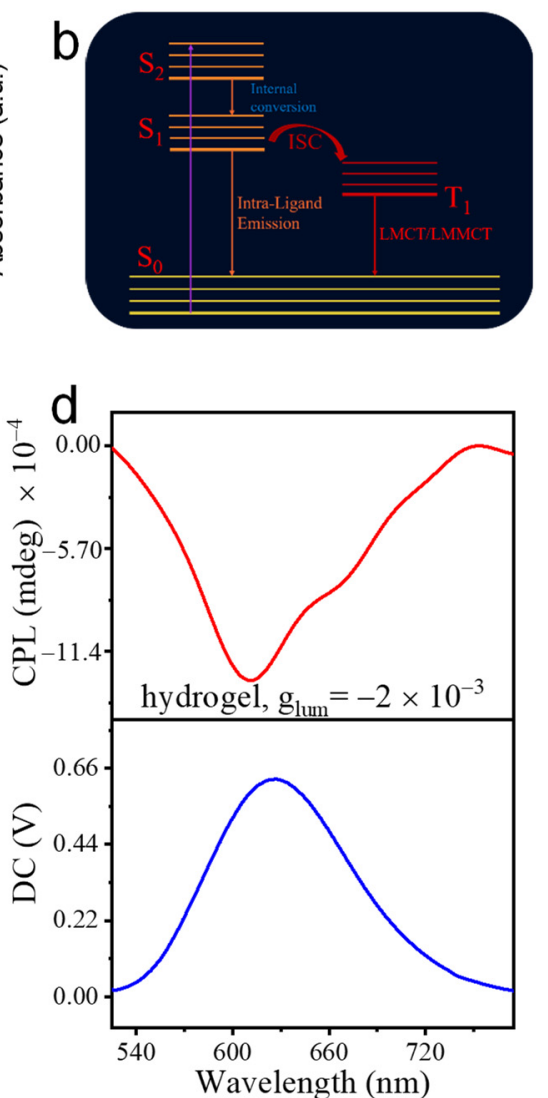

Figure 2. Study on the optical and chiral behavior of $\mathrm{Ag}_{9}-\mathrm{NCs} / \mathrm{DD}-5$ hydrogel. (a) Excitation (blue dotted line, $\lambda_{\mathrm{em}}=630 \mathrm{~nm}$ ), emission (red dotted line, $\lambda_{\mathrm{ex}}=490 \mathrm{~nm}$ ) spectra and UV-vis absorption (black line); (b) schematic diagram of the excite-state relaxation dynamics of the nanotubes; (c) CD spectrum of pure DD-5 and hydrogel, the bottom are the UV absorption spectra of pure DD-5 and hydrogel; (d) CPL spectrum of hydrogel, the DC value in the bottom spectrum stands for fluorescence intensity of hydrogel.

There are several reasons to prove that the system is phosphorescence produced by triple transitions: (i) the optimal excitation peak for $\mathrm{Ag}_{9}-\mathrm{NC}$ / DD-5 hydrogel is located at approximately $490 \mathrm{~nm}$, overlapping with the absorption peak of the charge transfer from the ligand to the metal of $\mathrm{Ag}_{9}-\mathrm{NC}$ caused by the addition of DD-5 (Figure 2a), 
inducing a phosphor with long lifetime emission [26]; (ii) the aromatic carboxyl group at room temperature is phosphorescence (RTP) molecule, the energy levels of singlet and triplet of $\mathrm{H}_{2}$ mba are very similar, and after the introduction of DD-5 through non-covalent interactions the amount of charge transfer from ligand-to-metal charge transfer (LMCT) increases, which makes intersystem crossing (ISC) prone to occur [27]; (iii) charge transfer can be caused by argentophilic interactions, which can also be attributed to the triplet state of argentophilic interactions with ligand-metal-mental charge transfer (LMMCT) [28,29]. Thus, it can be concluded that after DD-5 is added, DD-5 combines with Ag9-NCs through non-covalent interactions, which limits the intramolecular vibration and rotation of the $\mathrm{Ag}_{9}-\mathrm{NCs}$ ligand $\mathrm{mba}^{2-}$, reducing the non-radiative loss of triplet excitons, and promotes phosphorescence emission (Figure $2 b$ ).

Based on the chirality of the peptide DD-5, we next examined the chirality of $\mathrm{Ag}_{9}-$ NCs/DD-5 hydrogel. From the CD spectrum (Figure 2c), it is found that DD-5 has a strong negative Cotton effect at $204 \mathrm{~nm}$, while $\mathrm{Ag}_{9}-\mathrm{NCs} / \mathrm{DD}-5$ hydrogel has a relatively weak negative Cotton effect at $217 \mathrm{~nm}$, which indicates that the configuration after assembly has changed [30]. At the same time, the red shift $13 \mathrm{~nm}$ indicates that the chirality of DD-5 was successfully transferred to the assembly, and supramolecular chirality is obtained. Due to $\mathrm{Ag}_{9}-\mathrm{NCs} / \mathrm{DD}-5$ hydrogel having good luminescence performance and chirality, the circularly polarized luminescence (CPL) performance of the assembly is investigated. Generally speaking, the strength of CPL can be evaluated by the luminescence dissymmetry factor $\left(\mathrm{g}_{\text {lum }}\right)$, which is defined as $\mathrm{g}_{\text {lum }}=2 \times\left(I_{L}-I_{R}\right) /\left(I_{L}+I_{R}\right)$, where $I_{L}$ and $I_{R}$ refer to the intensity of left- and right-hand CPL, respectively. From the CPL spectrum (Figure 2d), the assembly has good CPL performance and asymmetry factor glum is $-2.0 \times 10^{-3}$, indicating that $\mathrm{Ag}_{9}-\mathrm{NCs} / \mathrm{DD}-5$ hydrogel with a negative Cotton effect displayed left-handed CPL.

\subsection{Structure and Mechanism Analysis of the Hydrogel}

To dissect the self-assembly mechanism of $\mathrm{Ag}_{9}-\mathrm{NCs} / \mathrm{DD}-5$ hydrogels, it is essential to analyze the composition of supramolecular assembly. The peak splitting results of $\mathrm{C}_{1 \mathrm{~s}}$, $\mathrm{N}_{1 \mathrm{~s}}, \mathrm{O}_{1 \mathrm{~s}}, \mathrm{~S}_{2 \mathrm{p}}$ and $\mathrm{Ag}_{3 \mathrm{~d}}$ for $\mathrm{Ag}_{9}-\mathrm{NCs} / \mathrm{DD}-5$ xerogel in XPS indicate that the hydrogel is formed by $\mathrm{Ag}_{9}-\mathrm{NCs}$ and DD-5 (Figures $3 \mathrm{a}$ and S4). Moreover, $\mathrm{Ag}_{9}-\mathrm{NCs} / \mathrm{DD}-5$ xerogel and $\mathrm{Ag}_{9}$-NCs powder have the similar signals in $\mathrm{Ag} 3 \mathrm{~d}_{5 / 2}$ and $\mathrm{Ag} 3 \mathrm{~d}_{3 / 2}$, indicating that $\mathrm{Ag}_{9}$-NCs do not undergo chemical or structural conversions during gelation (Figure $3 \mathrm{~b}$ ). In order to understand the deposition pattern and spatial structure of the hydrogel, SAXS and XRD were carried out. For the SAXS result of $\mathrm{Ag}_{9}-\mathrm{NCs} / \mathrm{DD}-5$ xerogel, four diffraction peaks are found at $q=10.59,9.48,6.64$ and $4.66 \mathrm{~nm}^{-1}$ with a scattering factor $q$ ratio of $1: \sqrt{ } 2: 2: \sqrt{ } 5$, which is a typical tetragonal phase stack (Figure 3c) [31]. In addition, the smallest repeating unit of its aggregate $d=1.35 \mathrm{~nm}$, which is equivalent to the size of $\mathrm{Ag}_{9}$-NCs. Considering the length of the $\mathrm{Ag}_{9}-\mathrm{NC}$ ligand $\mathrm{mba}^{2-}$ ligand $(\sim 6.5 \AA)$ and the length of DD- 5 molecule, the smallest repeating unit of $1.35 \mathrm{~nm}$ indicates a strong crossover between adjacent $\mathrm{Ag}_{9}-\mathrm{NCs}$ and DD-5, supporting the $\pi-\pi$ stacking form of $\mathrm{Ag}_{9}-\mathrm{NCs}$.

As shown in the XRD spectrum (Figure 3d), the $\mathrm{Ag}_{9}-\mathrm{NCs} / \mathrm{DD}-5$ xerogel has several relatively significant peaks were recorded in the range of $20-45^{\circ}$. The diffraction peaks at $2 \theta=22.14^{\circ}, 28.62^{\circ}$ and $34.10^{\circ}$ correspond to $\pi-\pi$ stacking (peak at $\boldsymbol{\Delta} 4.0 \AA$ ), $\mathrm{Ag}-\mathrm{Ag}$ (peak at - $3.1 \AA$ ), and Ag-S (peak at - 2.6 $⿱$ A) and other possible interplanar distances [32,33], which indicate that the presence of $\pi-\pi$ stacking and $\mathrm{Ag}-\mathrm{Ag}$ interactions contribute to an ordered arrangement in the assembled hydrogel. In contrast, the XRD of lyophilized $\mathrm{Ag}_{9}-\mathrm{NCs}$ solution and pure DD-5 only showed a diffuse reflection peak, indicating that they are of an amorphous nature. Based on the above data, we can conclude that the self-assembly process is closely related to the non-covalent interactions (H-bond, $\pi-\pi$ stacking) between $\mathrm{Ag}_{9}-\mathrm{NCs}$ and DD-5 and argentophilic interactions $[\mathrm{Ag}(\mathrm{I})-\mathrm{Ag}(\mathrm{I})]$ between $\mathrm{Ag}_{9}-\mathrm{NCs}$, and finally highly ordered fluorescent nanotubes are obtained. 

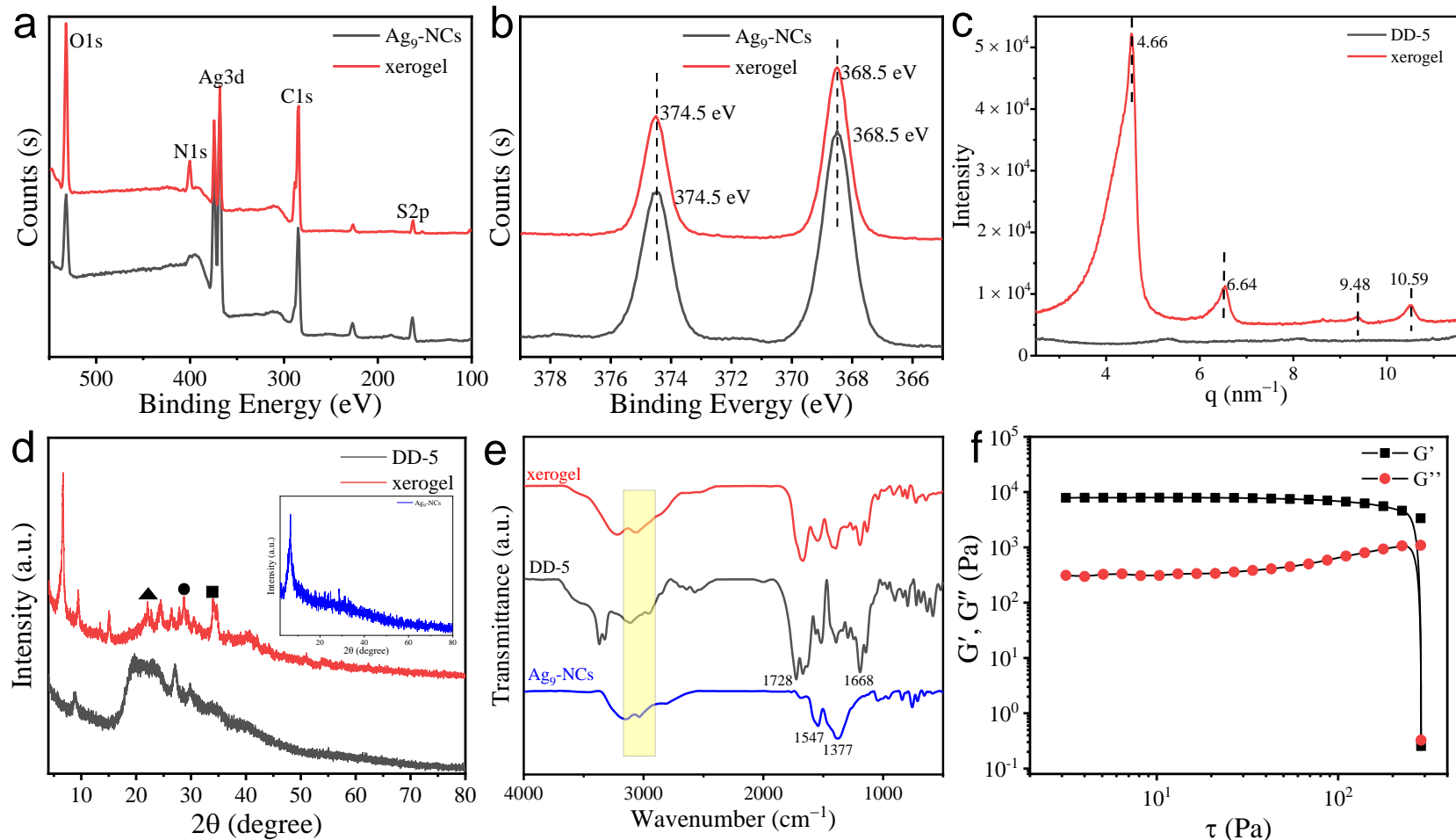

Figure 3. The structure characterization results of $\mathrm{Ag}_{9}-\mathrm{NCs} / \mathrm{DD}-5$ xerogel (or hydrogel). (a) XPS spectra of lyophilized $\mathrm{Ag}_{9}-\mathrm{NCs}$ and xerogel; (b) High-resolution XPS spectra of Ag element; (c) SAXS results of DD-5 and xerogel; (d) XRD results of DD-5 and xerogel, the inset shows the result of lyophilized $\mathrm{Ag}_{9}-\mathrm{NCs}$; (e) FT-IR spectra of a lyophilized $\mathrm{Ag}_{9}-\mathrm{NCs}$, DD-5 and xerogel; (f) stress sweep test at $f=1 \mathrm{~Hz}$ for the hydrogel Study on the optical and chiral behavior of $\mathrm{Ag}_{9}-\mathrm{NCs} / \mathrm{DD}-5$ hydrogel.

FT-IR was performed to explore the non-covalent forces between $\mathrm{Ag}_{9}-\mathrm{NCs}$ and DD-5 in the self-assembly (Figure 3d). For pure $\mathrm{Ag}_{9}-\mathrm{NCs}$ powder, 1537 and $1377 \mathrm{~cm}^{-1}$ are assigned to the antisymmetric and symmetric stretching vibrations of $\mathrm{C}=\mathrm{O}$ in the ligand $\mathrm{mba}^{2-}$ (Figure 3e) [34]. For pure DD-5 powder, the peak at $1410-1260 \mathrm{~cm}^{-1}$ is assigned to the in-plane curvature of the free carboxyl group, the peaks at 1668 and $1728 \mathrm{~cm}^{-1}$ belong to the amide I band, which is attributed to the stretching vibration of the peptide backbone, and the peak at $3370-3320 \mathrm{~cm}^{-1}$ is attributed to the stretching vibration of N-H. In $\mathrm{Ag}_{9}-\mathrm{NCs} / \mathrm{DD}-5$ xerogel, it was found that the $\mathrm{C}=\mathrm{O}$ of the $\mathrm{Ag}_{9}-\mathrm{NCs}$ ligand showed a significant red shift, the DD-5 amide I band peak disappeared and the free carboxyl group in-plane curvature peak weakened or even disappeared, indicating that there are hydrogen bonds between $\mathrm{Ag}_{9}-\mathrm{NCs}$ and DD-5. Moreover, the widening of the stretching vibration absorption band of 3200-3000 $\mathrm{cm}^{-1}$ belongs to $-\mathrm{OH}$, which also proves the formation of hydrogen bonds in this system [35].

The rheological characteristics are of great significance to supramolecular materials in the gel state, so we next tested the rheological properties of $\mathrm{Ag}_{9}-\mathrm{NCs} / \mathrm{DD}-5$ hydrogel to evaluate the mechanical properties of the hydrogel [36]. In the stress scan, the storage modulus $\left(G^{\prime}\right)$ is much larger than the loss modulus $\left(G^{\prime \prime}\right)$, indicating that the hydrogel exhibits solid-like nature (Figure $3 \mathrm{f}$ ). The yield stress corresponds to the transition from gel to fluid, that is, the network structure of the gel is destroyed [37], and $\mathrm{Ag}_{9}-\mathrm{NCs} / \mathrm{DD}-5$ hydrogel basically remains unchanged before reaching the yield stress of $285 \mathrm{~Pa}$, indicating that the formed hydrogel has high rigidity and resistance to damage ability. In the frequency sweep experiment, the storage modulus $\left(G^{\prime}\right)$ and loss modulus $\left(G^{\prime \prime}\right)$ of the hydrogel remained basically unchanged, and $\mathrm{G}^{\prime}(2300 \mathrm{~Pa})$ was much larger than $\mathrm{G}^{\prime \prime}(115 \mathrm{~Pa})$, indicating that $\mathrm{Ag}_{9}$-NCs /DD-5 hydrogel has a good mechanical strength (Figure S5a).

TGA was performed to explore the thermal stability of the hydrogel (Figure S5b). The weight loss of the xerogel sample before $100{ }^{\circ} \mathrm{C}$ can be attributed to water loss. The 
weight loss at $200-285^{\circ} \mathrm{C}$ is attributed to the vaporization of DD-5 carbon and the removal of oxidized functional groups (the first stage decomposition temperature of pure DD-5 at $174{ }^{\circ} \mathrm{C}$ ), together with the decomposition of $\mathrm{H}_{2} \mathrm{mba}$ (the decomposition temperature of lyophilized $\mathrm{Ag}_{9}-\mathrm{NC}$ s ligand $\mathrm{H}_{2} \mathrm{mba}$ is $\left.181^{\circ} \mathrm{C}\right)$. Compared with the original DD-5 and $\mathrm{Ag}_{9}$-NCs, the decomposition temperature of $\mathrm{Ag}_{9}-\mathrm{NCs} / \mathrm{DD}-5$ xerogel increased slightly $\left(200{ }^{\circ} \mathrm{C}\right)$, indicating that the thermal stability of the xerogel was further improved.

Based on the above results, it can be concluded that DD-5 and Ag-NCs were successfully co-assembled to obtain highly stable hydrogel. The hydrogel consists of highly ordered hollow nanotubes with a little spiral forming a stable three-dimensional network. We can propose the formation mechanism of nanotubes: (i) After the addition of DD-5, the rotational vibration of the $\mathrm{mba}^{2-}$ is restricted by H-bond formed which was surmised as being further divided in several parts, such as $-\mathrm{COO}^{-}$of $\mathrm{mba}^{2-}$ with $-\mathrm{OH}$ (or $-\mathrm{NH}-$ ) of DD-5, and/or $-\mathrm{OH}$ of protonated $\mathrm{mba}^{2-}\left(\mathrm{H}_{2} \mathrm{mba}\right)$ with $-\mathrm{COO}^{-}$of DD-5 and so on. (ii) The adjacent components with $\mathrm{Ag}(\mathrm{I})$-rich surface led to the strong argentophilic interactions between $\mathrm{Ag}_{9}$-NCs which induces the formation of highly oriented nanotubes. The $\pi-\pi$ stacking of adjacent ligands also contributes to the formation of spiral nanotubes. Therefore, the assembly process of hollow spiral nanotubes is controlled by inter-ligand non-covalent interactions (e.g., H-bond, $\pi-\pi$ stacking) and argentophilic interactions between $\mathrm{Ag}_{9}$-NCs.

\subsection{Kinetic Tracing of the Formation of $A g_{9}-N C s / D D-5$ Hydrogel}

In order to explore the relationship between the gelation process and fluorescent properties of $\mathrm{Ag}_{9}-\mathrm{NC}$ /DD-5 hydrogel, we followed the kinetic tracking of the self-assembly (Figure $4 \mathrm{~d}$ ). TEM showed the evolution of the morphology during the gelation (Figure 4a). At $1 \mathrm{~min}$, the self-assembled body is a small particle of Ag9-NCs combined with DD-5, there is no fluorescence emission (Figure $4 \mathrm{a}, \mathrm{c}$ ); The small particles self-assemble into a hollow short rod structure with a length of about $500 \mathrm{~nm}$ in $5 \mathrm{~min}$, and weak fluorescence appears at this time; at $30 \mathrm{~min}$, the hollow short rod structure further grows into nanotubes with a length of about $1 \mu \mathrm{m}$, and the fluorescence of the nanotubes is obviously enhanced; nanotubes with a little spiral structure are about $2 \mu \mathrm{m}$ in length at $3 \mathrm{~h}$, and the fluorescence is continually increased compared with that at $30 \mathrm{~min}$, but it is not much different from the final state fluorescence. Therefore, we believe that fluorescence emission is inseparable from the gelation process, that is, the increase in fluorescence intensity is caused by the transition from loose assembly to tightly packed spiral nanotubes. Based on the above results, we believe that in the presence of argentophilic interactions and non-covalent forces (H-bond, $\pi-\pi$ stacking), a tightly ordered assembly structure is formed which spatially limits the vibration and rotation of $\mathrm{Ag}_{9}-\mathrm{NC}$ ligands, thus triggers the AIE effect of the $\mathrm{Ag}_{9}-\mathrm{NC}$ s and induces fluorescence. That is, as the order of the assembled structure of $\mathrm{Ag}_{9}$-NCs/DD-5 hydrogel increases, the fluorescence gradually increases.

\subsection{Temperature Sensing}

Optical sensors have the advantages of wireless operation and imaging in harsh environments. Moreover, it is very important to realize temperature monitoring in scientific production, which also promotes the development of temperature sensing. The ultra-small size, good biocompatibility and colloidal stability of metal NCs are considered to be good materials for the development of high-intensity fluorescence thermometers. However, temperature sensors based on metal NCs are mainly concentrated in solution and gel states, while solid-state temperature sensors are rarely explored. In addition, most solid-state phosphorescent temperature sensing materials have poor photoluminescence capabilities at high temperatures, and the fluorescence generally disappears when the temperature is higher than $100{ }^{\circ} \mathrm{C}$ [38-40]. Therefore, it is particularly important to develop a solid material with good photoluminescence ability at high temperature. Based on this, we freeze-dried the hydrogel to obtain phosphorescent xerogel, and explored the luminescence of the xerogel with temperature changes in detail. 

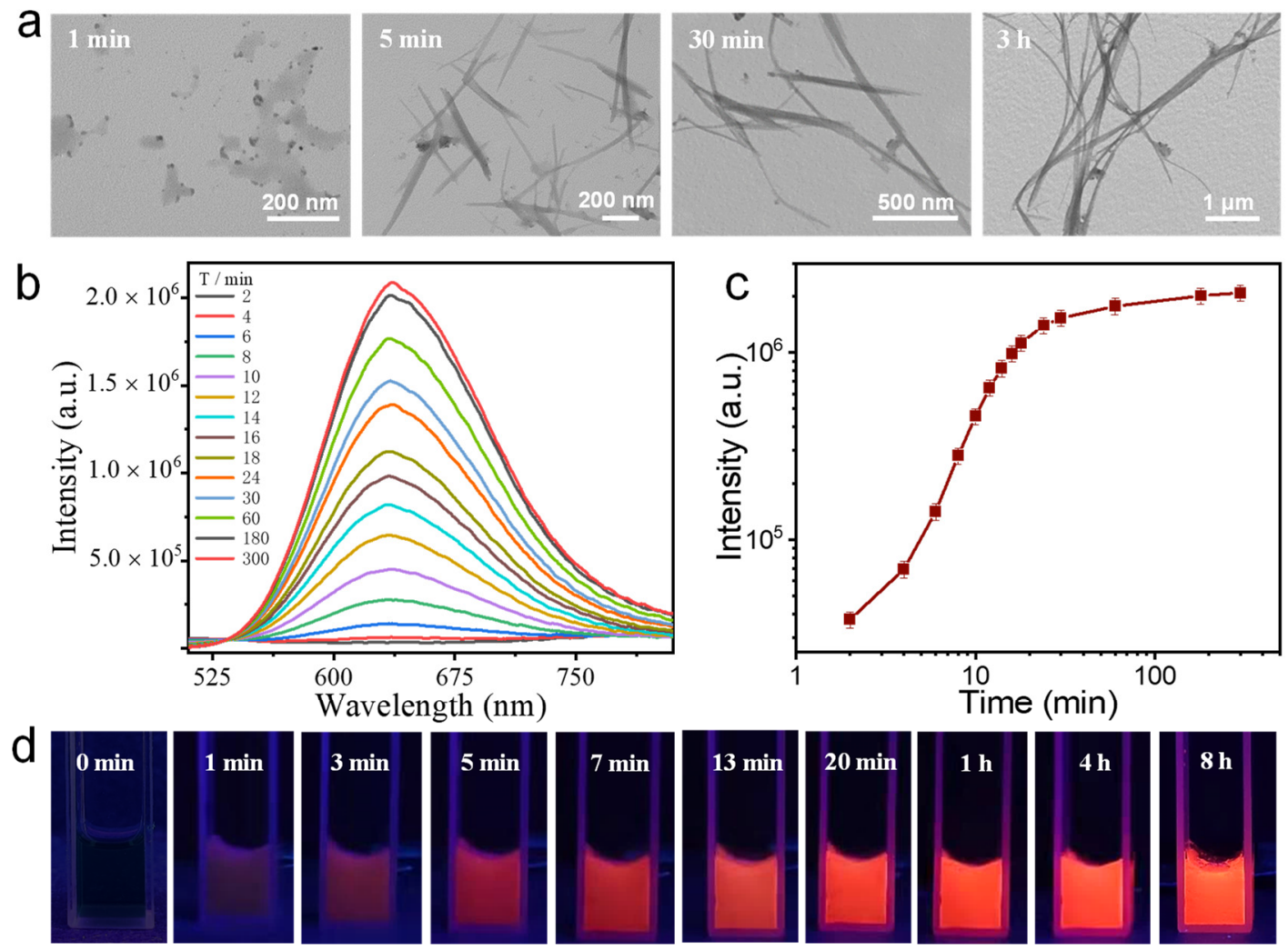

\section{Increasing Time}

Figure 4. $\mathrm{Ag}_{9}$-NCs/DD-5 hydrogel kinetic tacking. (a) TEM images of hydrogel changing over time; (b) Time-varying PL spectrum of hydrogel under excitation at $490 \mathrm{~nm}$; (c) PL intensity graph at $\lambda=630 \mathrm{~nm}\left(\lambda_{\text {ex }}=490 \mathrm{~nm}\right)$; (d) Photographs of the formation process of the hydrogel irradiated with 365 nm UV light.

As the temperature rises from $-160{ }^{\circ} \mathrm{C}$ to $260{ }^{\circ} \mathrm{C}$, the PL intensity of Ag9-NCs/DD-5 xerogel continues to decrease and the fluorescence peak position also appears slightly blue-shifted (Figure $5 \mathrm{a}-\mathrm{c}$ ). The reasons for this change are as follows: (i) as the temperature increases, the oxygen molecules collide with their luminescent center; (ii) the high temperature weakens the Ag-S bond between the $\mathrm{H}_{2} \mathrm{mba}$ and the sliver core, resulting in a decrease in the charge from the ligand to the sliver core of $\mathrm{Ag}_{9}-\mathrm{NCs}$; (iii) as the temperature rises, non-covalent interactions (H-bond, $\pi-\pi$ stacking) gradually weaken, resulting in a compact network being stretched, the rotation limit of the $\mathrm{mba}^{2-}$ ligand is reduced, non-radiative relaxation is prone to occur; and (iv) as the temperature increases, the conformation of DD-5 changes, causing $\mathrm{Ag}_{9}-\mathrm{NC}$ s to be directly exposed to the air and oxidized to larger silver nanoparticles at high temperatures. All these factors lead to the decrease of fluorescence intensity and blue shift of fluorescence peak. Figure $5 \mathrm{~d}$ shows the change in PL intensity over the entire temperature range, which can be described by two linear parts with an inflection point at $80{ }^{\circ} \mathrm{C}$ (Figure $5 \mathrm{~d}$ ). The xerogel satisfies a good linear relationship in the low temperature range from $-160{ }^{\circ} \mathrm{C}$ to $80^{\circ} \mathrm{C}$ and the high temperature range from $80{ }^{\circ} \mathrm{C}$ to $260{ }^{\circ} \mathrm{C}$, which will have a wide range of applications in the field of both low and high temperature fluorescence sensing. 

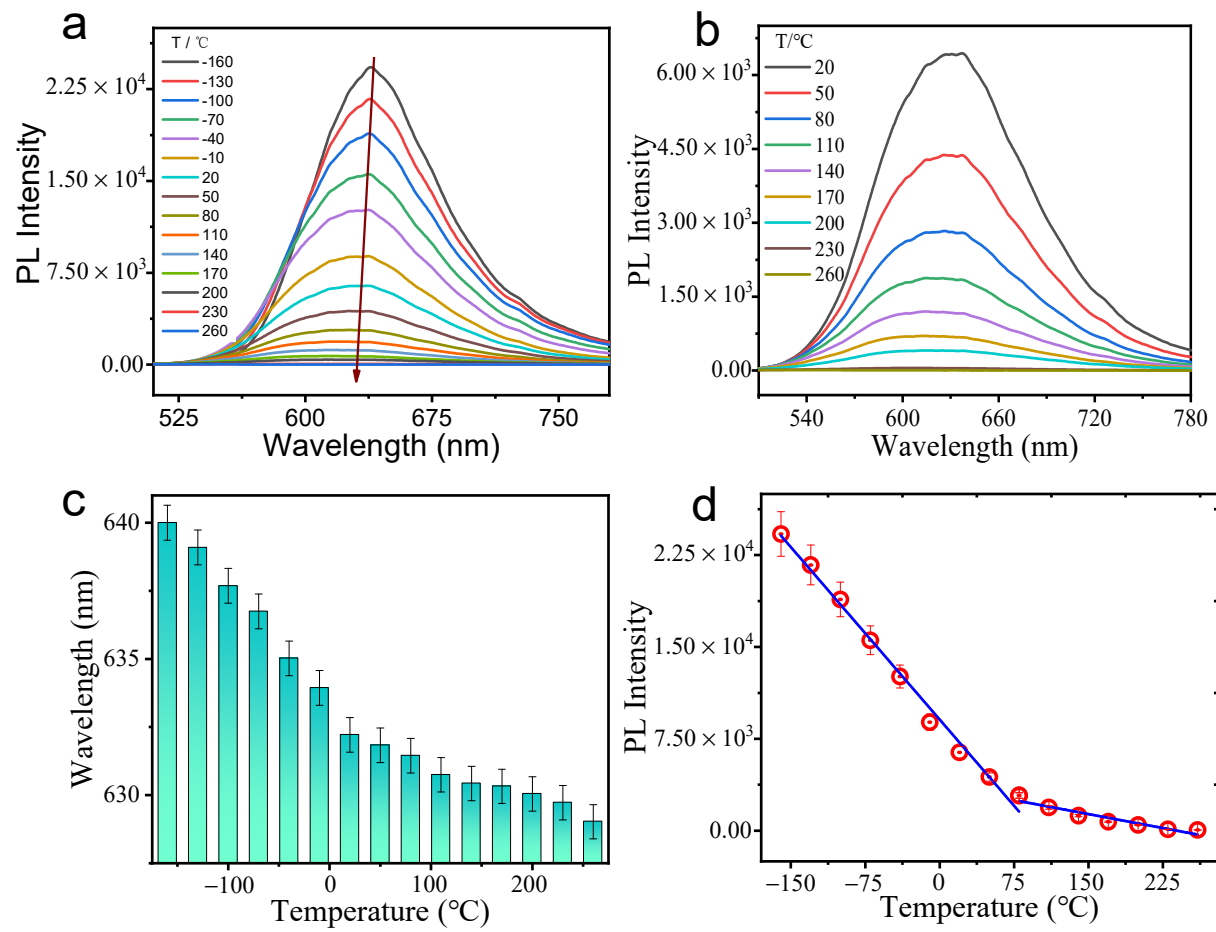

Figure 5. Fluorescence change of xerogel with temperature. $(\mathbf{a}, \mathbf{b})$ Fluorescence spectra with increasing temperature; (c) PL peak position changes with increasing temperature; (d) The corresponding PL intensity under different temperature.

\subsection{The Detection of L-Arg and D-Arg}

It is well-known that amino acids play an important role in the human body. Among various amino acids, Arg can stimulate the secretion of hormones such as insulin, growth hormone, glucagon and prolactin. At the same time, Arg content is also one of the key parameters for evaluating the pathophysiology of hyperammonemia and astrocytes cultured with aggregated nerve cells [41-43]. Therefore, it is very important for human health to detect Arg with high selectivity and sensitivity. Fortunately, Ag ${ }_{9}$-NCs/DD-5 hydrogel with good biocompatibility can be used as a biosensor to detect L-Arg and D-Arg. It can be found that the addition of L-Arg and D-Arg can completely quench the fluorescence of $\mathrm{Ag}_{9}$ NCs/DD-5 hydrogel, while when the other amino acids (L-Ala, L-His, L-Cys, L-Phe, L-Gln, L-Ser, L-Thr, L-Asn, L-Val and Gly) were added, the fluorescence intensity changed slightly (Figure 6a-c), we then take L-Arg as an example to investigate in detail. With the increase of the concentration of L-Arg, the fluorescence intensity gradually decreases (Figure 6d), $\mathrm{I}_{0} / \mathrm{I}$ have a linear relationship with L-Arg at a lower concentration, and the detection line calculated from 38 /slope is $240 \mu \mathrm{M}$ (Figure 6e), indicating that $\mathrm{Ag}_{9}-\mathrm{NCs} / \mathrm{DD}-5$ hydrogel can detect L-Arg with high sensitivity. Adding L-Arg and other amino acids together to the hydrogel system, it could be found that even in the presence of other amino acids, L-Arg could still quench its fluorescence, indicating that $\mathrm{Ag}_{9}-\mathrm{NCs} / \mathrm{DD}-5$ hydrogel also has high selectivity for L-Arg (Figure 6c). 

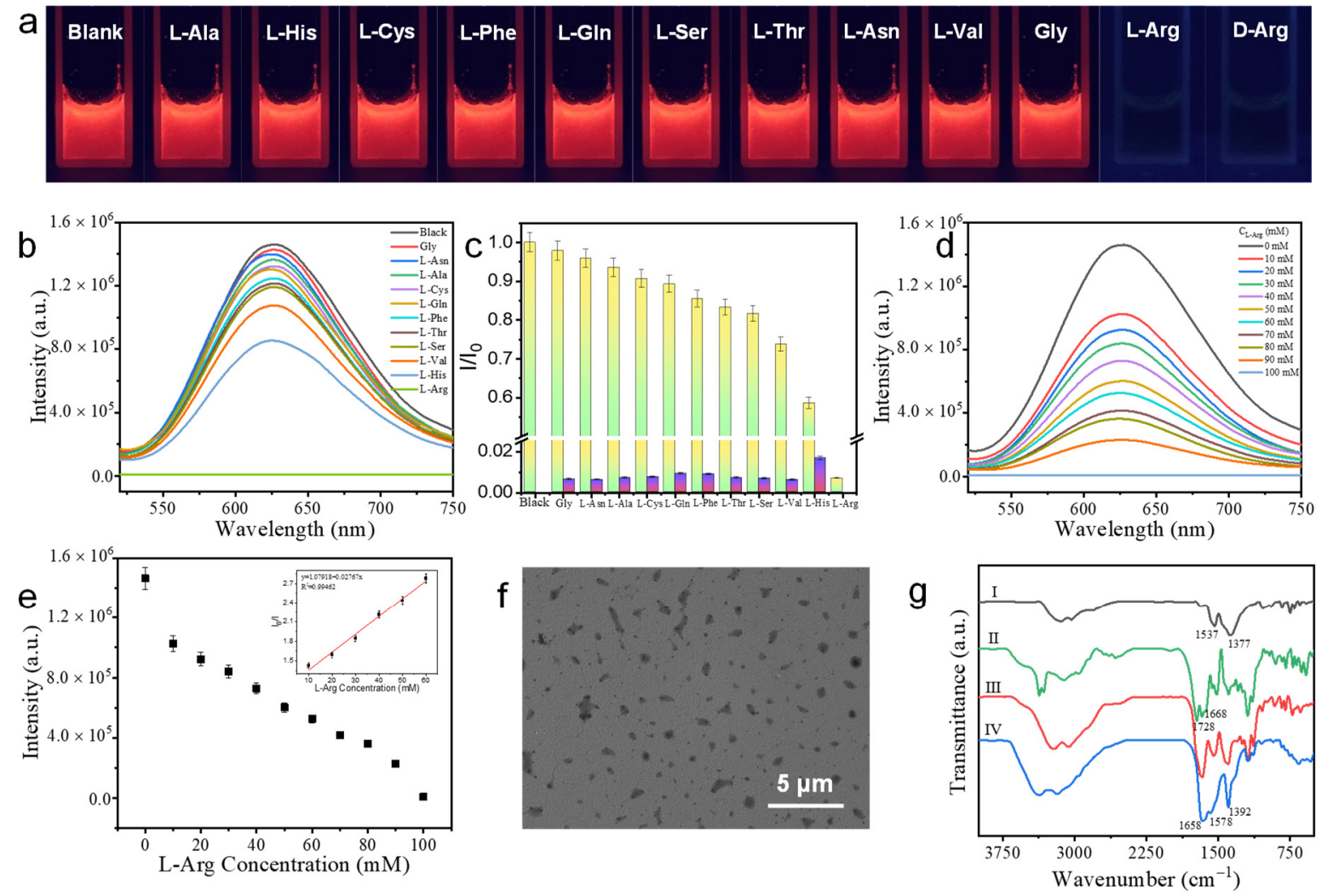

Figure 6. Detection of arginine by hydrogel. (a) Photographs of the samples observed under $365 \mathrm{~nm}$ UV lamp with the addition of amino acids; (b) PL spectra of nanotubes with the addition of amino acids; (c) Selectivity of nanotubes toward L-Arg, the lighter color is the fluorescence intensity after adding different kinds of amino acids, the darker color is the fluorescence intensity after adding L-Arg to the above sample; (d,e) Concentration-dependent fluorescence spectra and fluorescence intensity with the addition of different contents of L-Arg, inset: Stern-Volmer quenching curve of the fluorescence intensity of the hydrogel at $630 \mathrm{~nm}$ against L-Arg concentration; (f) TEM image of L-Arg added to $\mathrm{Ag}_{9}-\mathrm{NCs} / \mathrm{DD}-5$ hydrogel; (g) FT-IR spectrum, where I represents lyophilized $\mathrm{Ag}_{9}-\mathrm{NC}$; II represents DD-5; III represents $\mathrm{Ag}_{9}-\mathrm{NCs} / \mathrm{DD}-5$ xerogel; IV represents freeze-dried sample after adding L-Arg to $\mathrm{Ag}_{9}-\mathrm{NCs} / \mathrm{DD}-5$ hydrogel.

In addition, it was found from the TEM image that the nanotubes with a little spiral disappeared after the addition of L-Arg, and more particles with superfine nanowires appeared (Figure 6f), indicating that the addition of L-Arg destroyed the ordered structure of the hydrogel. From FT-IR results, as shown in Figure $6 \mathrm{~g}$, after the addition of L-Arg, there is a reappearance of peaks at 1658 and $1578 \mathrm{~cm}^{-1}$ belonging to the amide I band (its red shift is attributed to the addition of L-Arg) and at $1392 \mathrm{~cm}^{-1}$ belonging to the symmetric vibrational absorption peak of the $\mathrm{C}=\mathrm{O}$ group in $\mathrm{mba}^{2-}$, indicating that the addition of $\mathrm{L}$-Arg destroyed the intermolecular $\mathrm{H}$-bond and reduce the radiation relaxation of the $\mathrm{Ag}_{9}-\mathrm{NC}$ ligand $\mathrm{mba}^{2-}$ and made the fluorescence disappear. In the FT-IR, it is found that L-Arg is added to break the H-bond between $\mathrm{Ag}_{9}-\mathrm{NCs}$ and DD-5 to achieve the purpose of detection, which has nothing to do with the molecular configuration of Arg. Therefore, we reasonably believe that $\mathrm{Ag}_{9}-\mathrm{NCs} / \mathrm{DD}-5$ hydrogel has good detection capabilities for both L-Arg and D-Arg.

\section{Conclusions}

In this work, an $\mathrm{Ag}_{9}$-NCs/DD-5 hydrogel with highly ordered hollow nanotubes with a little spiral and phosphorescent emission was successfully obtained by supramolecular self-assembly through inter-ligand non-covalent interactions (H-bond, $\pi-\pi$ stacking) and argentophilic interactions $[\mathrm{Ag}(\mathrm{I})-\mathrm{Ag}(\mathrm{I})]$ between $\mathrm{Ag}_{9}-\mathrm{NCs}$. After self-assembly, the 
transfer of chirality of DD-5 to supramolecular chirality of $\mathrm{Ag}_{9}-\mathrm{NC} / \mathrm{DD}-5$ hydrogel was successfully realized together with good CPL performance. In addition, $\mathrm{Ag}_{9}-\mathrm{NC} / \mathrm{DD}-5$ xerogel can still emit fluorescence at $200{ }^{\circ} \mathrm{C}$, making it an ideal choice for a new generation of luminous temperature-sensing agents both in low and high temperatures. Moreover, $\mathrm{Ag}_{9}$-NCs/DD-5 hydrogel has selectivity and sensitivity for the detection of L-Arg and D-Arg. Our work implied that supramolecular self-assembled materials for metal NCs not only have potential applications in the field of fluorescence sensing, but also have huge application prospects in the field of biological detection.

Supplementary Materials: The following supporting information can be downloaded at: https: / / www.mdpi.com/article/10.3390/nano12030424/s1, Figure S1: Co-assembled primitive photos and co-assembled phase behavior photos, Figure S2: TEM and SEM images at different concentrations of DD-5, Figure S3: PL decay curve of lyophilized $\mathrm{Ag}_{9}-\mathrm{NCs}$ solution and $\mathrm{Ag}_{9}-\mathrm{NCs} / \mathrm{DD}-5$ hydrogel, Figure S4: High-resolution XPS spectra of the $\mathrm{Ag}_{9}-\mathrm{NCs} / \mathrm{DD}-5$ xerogel, Figure S5: Hydrogel rheology and xerogel TGA, Table S1: Lifetime of the powder of lyophilized $\mathrm{Ag}_{9}$-NCs solution, Table S2. Lifetime of $\mathrm{Ag}_{9}$-NCs/DD-5 hydrogel.

Author Contributions: W.W.: Conceptualization, methodology, formal analysis, investigation, writing - reviewing and editing; Z.W.: formal analysis, writing — reviewing and editing; D.S.: methodology, writing-reviewing and editing; S.L.: conceptualization, writing-reviewing and editing; Q.D.: resources, funding acquisition; X.X.; writing — reviewing and editing, supervision, funding acquisition. All authors have read and agreed to the published version of the manuscript.

Funding: We gratefully acknowledge the financial support from the National Natural Science Foundation of China (21972077), and Key Technology Research and Development Program of Shandong (2019GGX102019).

Data Availability Statement: Not applicable.

Conflicts of Interest: The authors declare no conflict of interest.

\section{References}

1. Kailasa, S.; Borse, S.; Koduru, J.; Muthy, Z. Biomolecules as Promising Ligands in the Synthesis of Metal Nanoclusters: Sensing, Bioimaging and Catalytic Applications. Trends Environ. Anal. Chem. 2021, 32, e00104. [CrossRef]

2. Han, S.; Zhao, Y.; Zhang, Z.; Xu, G. Recent Advances in Electrochemiluminescence and Chemiluminescence of Metal Nanoclusters. Molecules 2020, 20, 5208. [CrossRef] [PubMed]

3. Shan, P.; Yang, J.; Zang, Z.; Zhao, Q.; Cheng, Y.; Li, L.; Yang, X.; Yu, X.; Lu, Z.; Zhang, X. Effects of Silver Nanoclusters on the Spectral Properties for Fluorescein Isothiocyanate with Restrained Photobleaching. Appl. Surf. Sci. 2021, 548, 14928-14938. [CrossRef]

4. Zhang, Y.; Zhang, C.; Xu, C.; Wang, X.; Liu, C.; Waterhouse, G.I.N.; Wang, Y.; Yin, H. Ultrasmall Au Nanoclusters for Biomedical and Biosensing Applications: A Mini-review. Talanta 2019, 200, 432-442. [CrossRef] [PubMed]

5. Li, J.; Zhu, J.; Xu, K. Fluorescent Metal Nanoclusters: From Synthesis to Applications. TrAC Trends Anal. Chem. 2014, 58, 90-98. [CrossRef]

6. Xie, Z.; Sun, P.; Wang, Z.; Li, H.; Yu, L.; Sun, D.; Chen, M.; Bi, Y.; Xin, X.; Hao, H. Metal-Organic Gels from Silver Nanoclusters with Aggregation-Induced Emission and Fluorescence-to-Phosphorescence Switching. Angew. Chem. Int. Ed. 2020, 59, $9922-9927$. [CrossRef]

7. Sun, P.; Wang, Z.; Bi, Y.; Sun, D.; Zhao, T.; Zhao, F.; Wang, W.; Xin, X. Self-assembly Driven Aggregation-Induced Emission of Silver Nanoclusters for Light Conversion and Temperature Sensing. ACS Appl. Nano Mater. 2020, 3, 2038-2046. [CrossRef]

8. Hu, X.; Zhang, X.; Gao, H.; Huang, Y. Cu-Based Metal-Organic Frameworks-Derived Copper Nanoclusters with Tunable Emission for Ratiometric pH Sensing. Sens. Actuators B Chem. 2022, 353, 131130-131140. [CrossRef]

9. Desai, M.; Basu, H.; Saha, S.; Singhal, R.; Kailasa, S. Fluorescence Enhancement of Bovine Serum Albumin Gold Nanoclusters from $\mathrm{La}^{3+}$ Ion: Detection of Four Divalent Metal Ions $\left(\mathrm{Hg}^{2+}, \mathrm{Cu}^{2+}, \mathrm{Pb}^{2+}\right.$ and $\left.\mathrm{Cd}^{2+}\right)$. J. Mol. Liq. 2021, 336, 116239-116249. [CrossRef]

10. Borse, S.; Murthy, Z.; Park, T.; Kailasa, S. Lysozyme-Decorated Gold and Molybdenum Bimetallic Nanoclusters for the Selective Detection of Bilirubin as a Jaundice Biomarker. ACS Appl. Nano Mater. 2021, 4, 11949-11959. [CrossRef]

11. Wen, Q.; Peng, J.; Liu, A.; Hu, Y.; Wang, J.; Ling, J.; Cao, Q. Fluorescent Silver Nanoclusters Stabilized in Guanine-Enhanced DNA Hybridization for Recognizing Different Small Biological Molecules. J. Lumin. 2020, 221, 117038-117046. [CrossRef]

12. Zhang, S.; Su, H.; Wang, Z.; Wang, L.; Zhao, Q.; Tung, C.; Sun, D.; Zheng, L. Anion-Templated Nanosized Silver Alkynyl Clusters: Cluster Engineering and Solution Behavior. Chem. Eur. J. 2017, 23, 3432-3437. [CrossRef] [PubMed]

13. Jia, X.; Li, J.; Wang, E. Supramolecular Self-assembly of Morphology-Dependent Luminescent Ag Nanoclusters. Chem. Commun. 2014, 50, 9565-9568. [CrossRef] [PubMed] 
14. Khanra, S.; Abdullah-Al Mamun, M.; Ferreira, F.F.; Ghosh, K.; Guha, S. Functionalized Self-Assembled Peptide Nanotubes with Cobalt Ferrite Nanoparticles for Applications in Organic Electronics. ACS Appl. Nano Mater. 2018, 1, 1175-1187. [CrossRef]

15. Khan, J.M.; Khan, M.S.; Qadeer, A.; Alsenaidy, M.A.; Ahmed, A.; Al-Shabib, N.A.; Khan, R.H. Cationic Gemini Surfactant (16-4-16) Interact Electrostatically with Anionic Plant Lectin and Facilitates Amyloid Fibril Formation at Neutral pH. Colloids Surf. A Physicochem. Eng. Asp. 2017, 522, 494-502. [CrossRef]

16. Fatouros, D.G.; Lamprou, D.A.; Urquhart, A.J.; Yannopoulos, S.N.; Viziranakis, I.S.; Zhang, S.; Koutsopoulos, S. Lipid-like Self-Assembling Peptide Nanovesicles for Drug Delivery. ACS Appl. Mater. Interfaces 2014, 6, 8184-8189. [CrossRef]

17. Xing, R.; Li, S.; Zhang, N.; Shen, G.; Mohwald, H.; Yan, X. Self-Assembled Injectable Peptide Hydrogels Capable of Triggering Antitumor Immune Response. Biomacromolecules 2017, 18, 3514-3523. [CrossRef]

18. Chen, X.; Zhang, M.; Wang, X.; Chen, Y.; Yan, Y.; Zhang, L.; Zhang, L. Peptide-Modified Chitosan Hydrogels Promote Skin Wound Healing by Enhancing Wound Angiogenesis and Inhibiting Inflammation. Am. J. Transl. Res. 2017, 9, $2352-2362$.

19. Xing, R.; Zou, Q.; Yan, X. Peptide-Based Supramolecular Colloids. Acta Phys. Chim. Sin. 2020, 36, 1909048-1909064.

20. Shen, J.; Xiao, Q.; Sun, P.; Feng, J.; Xin, X.; Yu, Y.; Qi, W. Self-Assembled Chiral Phosphorescent Microflowers from Au Nanoclusters with Dual-Mode pH Sensing and Information Encryption. ACS Nano 2017, 15, 4947-4955. [CrossRef]

21. Liu, J.; Yu, Y.; Wang, C.; Shen, J.; Feng, J.; Qi, W. Fabrication of a Chiral Luminescent Hydrogel from Gold Nanoclusters via Molecular Recognition. Chem. Commun. 2021, 57, 10202-10205. [CrossRef] [PubMed]

22. Chakraborty, P.; Ghosh, M.; Schnaider, L.; Adadi, N.; Ji, W.; Bychenko, D.; Dvir, T.; Adler-Abramovich, L.; Gazit, E. Composite of Peptide-Supramolecular Polymer and Covalent Polymer Comprises a New Multifunctional, Bio-Inspired Soft Material. Macromol. Rapid Commun. 2019, 40, 1900175. [CrossRef] [PubMed]

23. Wang, C.; Sun, Y.; Wang, J.; Xu, H.; Lu, J. Copper (II)-Mediated Self-Assembly of Hairpin Peptides and Templated Synthesis of CuS Nanowires. Chem. Asian J. 2015, 10, 1953-1958. [CrossRef] [PubMed]

24. Sun, P.; Wang, Z.; Sun, D.; Bai, H.; Zhu, Z.; Bi, Y.; Zhao, T.; Xin, X. pH-Guided Self-Assembly of Silver Nanoclusters with Aggregation-Induced Emission for Rewritable Fluorescent Platform and White Light Emitting Diode Application. J. Colloid Interface Sci. 2020, 564, 235-242. [CrossRef] [PubMed]

25. Bi, Y.; Wang, Z.; Liu, T.; Sun, D.; Godbert, N.; Li, H.; Hao, J.; Xin, X. Supramolecular Chirality from Hierarchical Self-assembly of Atomically Precise Silver Nanoclusters Induced by Secondary Metal Coordination. ACS Nano 2021, 15, 15910-15919. [CrossRef] [PubMed]

26. Heaven, M.W.; Dass, A.; White, P.S.; Holt, K.M.; Murray, R.W. Crystal Structure of the Gold Nanoparticle $\left[\mathrm{N}\left(\mathrm{C}_{8} \mathrm{H}_{17}\right)_{4}\right]$ [ $\mathrm{Au}_{25}\left(\mathrm{SCH}_{2} \mathrm{CH}_{2} \mathrm{Ph}\right)_{18}$ ]. J. Am. Chem. Soc. 2008, 130, 3754-3755. [CrossRef] [PubMed]

27. Bolton, O.; Lee, K.; Kim, H.; Lin, K.; Kim, J. Activating Efficient Phosphorescence from Purely Organic Materials by Crystal Design. Nat. Chem. 2011, 3, 205-210. [CrossRef]

28. Ni, W.; Qiu, Y.; Li, M.; Zheng, J.; Sun, R.W.Y.; Zhan, S.; Ng, S.W.; Li, D. Metallophilicity-Driven Dynamic Aggregation of a Phosphorescent Gold(I)-Silver(I) Cluster Prepared by Solution-Based and Mechanochemical Approaches. J. Am. Chem. Soc. 2014, 136, 9532-9535. [CrossRef]

29. Pyo, K.; Thanthirige, V.D.; Kwak, K.; Pandurangan, P.; Ramakrishna, P.; Lee, D. Ultrabright Luminescence from Gold Nanoclusters: Rigidifying the Au(I)-Thiolate Shell. J. Am. Chem. Soc. 2015, 137, 8244-8250. [CrossRef]

30. Zhao, Y.; Wang, J.; Deng, L.; Zhou, P.; Wang, S.; Wang, Y.; Xu, H.; Lu, J.R. Tuning the Self-Assembly of Short Peptides via Sequence Variations. Langmuir 2013, 29, 13457-13464. [CrossRef]

31. Xu, Y.; Zhang, Y.; Guo, Z.; Ren, J.; Wang, Y.; Peng, H. Flexible, Stretchable, and Rechargeable Fiber-Shaped Zinc-Air Battery Based on Cross-Stacked Carbon Nanotube Sheets. Angew. Chem. Int. Ed. 2015, 54, 15390-15394. [CrossRef] [PubMed]

32. Barreiro, E.; Casas, J.S.; Couce, M.D.; Laguna, A.; Lopez-de-Luzuriaga, J.M.; Monge, M.; Sanchez, A.; Sordo, J.; Lopez, E.M.V. A Novel Hexanuclear Silver(I) Cluster Containing a Regular Ag-6 Ring with Short Ag-Ag Distances and an Argentophilic Interaction. Dalton Trans. 2013, 42, 5916-5923. [CrossRef]

33. Wu, Z.; Du, Y.; Liu, J.; Yao, Q.; Chen, T.; Cao, Y.; Zhang, H.; Xie, J. Aurophilic Interactions in the Self-Assembly of Gold Nanoclusters into Nanoribbons with Enhanced Luminescence. Angew. Chem. Int. Ed. 2019, 58, 8139-8144. [CrossRef] [PubMed]

34. Cursino, A.C.T.; Gardolinski, J.E.F.D.; Wypch, F. Intercalation of Anionic Organic Ultraviolet Ray Absorbers into Layered Zinc Hydroxide Nitrate. J. Colloid Interface Sci. 2010, 347, 49-55. [CrossRef]

35. Moitessier, N.; Chapleur, Y. Modulation of the Relative Reactivities of Carbohydrate Secondary Hydroxyl Groups Modification of the Hydrogen Bond Network. Tetrahedron Lett. 2003, 44, 1731-1735. [CrossRef]

36. Shen, J.; Wang, Z.; Sun, D.; Liu, G.; Yuan, S.; Kurmoo, M.; Xin, X. Self-Assembly of Water-Soluble Silver Nanoclusters: Superstructure Formation and Morphological Evolution. Nanoscale 2017, 9, 19191-19200. [CrossRef]

37. Shen, X.; Wang, Y.; Zhao, E.; Yuan, W.; Liu, Y.; Lu, P.; Qin, A.; Ma, Y.; Sun, J.; Tang, B. Effects of Substitution with Donor-Acceptor Groups on the Properties of Tetraphenylethene Trimer: Aggregation-Induced Emission, Solvatochromism, and Mechanochromism. J. Phys. Chem. C 2013, 117, 7334-7347. [CrossRef]

38. Li, J.; Zhang, H.; Zhang, Y.; Zhou, W.; Liu, Y. Room-Temperature Phosphorescence and Reversible White Light Switch Based on a Cyclodextrin Polypseudorotaxane Xerogel. Adv. Opt. Mater. 2019, 7, 1900589. [CrossRef]

39. Zhu, Y.; Guan, Y.; Niu, Y.; Wang, P.; Chen, R.; Wang, Y.; Wang, P.; Xie, H. Ultralong Polymeric Room Temperature Phosphorescence Materials Fabricated by Multiple Hydrogen Bondings Resistant to Temperature and Humidity. Adv. Opt. Mater. 2021, 9, 2100782. [CrossRef] 
40. Wu, H.; Gu, L.; Baryshnikov, G.V.; Wang, H.; Minaev, B.F.; Agren, H.; Zhao, Y. Molecular Phosphorescence in Polymer Matrix with Reversible Sensitivity. ACS Appl. Mater. Interfaces 2020, 12, 20765-20774. [CrossRef]

41. Gorren, A.C.F.; Schmidt, K.; Mayer, B. Binding of L-arginine and Imidazole Suggests Heterogeneity of Rat Brain Neuronal Nitric Oxide Synthase. Biochemistry 2002, 41, 7819-7829. [CrossRef] [PubMed]

42. Senkevitch, E.; Cabrera-Luque, J.; Morizono, H.; Caldovic, L.; Tuchman, M. A Novel Biochemically Salvageable Animal Model of Hyperammonemia Devoid of N-acetylglutamate Synthase. Mol. Genet. Genom. 2012, 106, 160-168. [CrossRef] [PubMed]

43. Kapila, S.; Saba, M.; Lin, C.; Bawle, E.V. Arginine Deficiency-Induced Hyperammonemia in a Home Total Parenteral NutritionDependent Patient: A Case Report. JPEN J. Parenter. Enter. Nutr. 2001, 25, 286-288. [CrossRef] [PubMed] 